\title{
Sensitive immunoassays based on a monoclonal antibody for detection of marbofloxacin in milk
}

\author{
Meixia Luo, ${ }^{1}$ Keyu Xing, ${ }^{1}$ Zhen Guo, ${ }^{2}$ Debin Guo, ${ }^{2}$ Weihua Lai, ${ }^{1}$ and Juan Peng ${ }^{3 *}$ \\ ${ }^{1}$ State Key Laboratory of Food Science and Technology, Nanchang University, Nanchang 330047, China \\ ${ }^{2}$ Jiangxi Huangshanghuang Group Food Co. Ltd., Nanchang 330009, China \\ ${ }^{3}$ School of Food Science, Nanchang University, Nanchang 330047, China
}

\section{ABSTRACT}

Marbofloxacin (MBF) is a key class of synthetic fluoroquinolone antibiotic that is commonly used as a veterinary drug. However, excess residue of MBF in animal-derived food samples, such as milk, is harmful to consumers. In this study, $4 \mathrm{mAb}$ against $\mathrm{MBF}$, namely, M4E3, M7A6, M3C7, and M5C6, were produced. Indirect competitive (ic) ELISA revealed that the M4E3 exhibited the highest sensitivity with a half-maximal inhibitory concentration $\left(\mathrm{IC}_{50}\right)$ of $0.07 \mathrm{ng} / \mathrm{mL}$ and a limit of detection of $0.01 \mathrm{ng} / \mathrm{mL}$ for detection of MBF. The results of the cross-reactivity experiment revealed that the M4E3 could detect lomefloxacin, ofloxacin, fleroxacin, pefloxacin, danofloxacin, and enrofloxacin sensitively with $\mathrm{IC}_{50}$ of $0.02,0.07,0.18,0.27,0.30$, and $0.32 \mathrm{ng} / \mathrm{mL}$, respectively. Meanwhile, a cross-reactivity experiment showed that the M4E3 had a crossover rate of more than $20 \%$ with these fluoroquinolone analogs. A weak crossover rate below $1.11 \%$ was observed with 14 other fluoroquinolone analogs. The recovery rate of MBF in milk ranged from $72.28 \%$ to $129.19 \%$, which showed that the developed indirect competitive ELISA was effective in detecting MBF in milk. Furthermore, a visual colloidal gold-based immunochromatographic assay was developed for detecting MBF with a cut-off value of $1 \mathrm{ng} / \mathrm{mL}$ in both phosphate-buffered saline and a milk sample by using this mAb. Given this sensitive $\mathrm{mAb}$, both indirect competitive ELISA and colloidal gold-based immunochromatographic assay could be effective screening tools for detection of MBF in milk.

Key words: marbofloxacin, monoclonal antibody, indirect competitive ELISA, colloidal gold-based immunochromatographic assay

Received December 23, 2019.

Accepted May 6, 2020.

*Corresponding author: pengjuan2016@163.com

\section{INTRODUCTION}

Fluoroquinolones (FQ) are a kind of highly effective broad-spectrum antibacterial drugs that are mainly used in the prevention and treatment of human and animal diseases (Pham et al., 2019). Fluoroquinolones inhibit the synthesis of bacterial DNA by binding to DNA gyrase or topoisomerase, thereby producing an antibacterial effect against gram-negative and grampositive bacteria (Rusch et al., 2017). Marbofloxacin (MBF) is a class of FQ that has been commonly used in the treatment of various microbial infections in animals (Balikci et al., 2008; Hoeltig et al., 2018; Altan et al., 2019; Dokuzeylül et al., 2019). However, the abuse of FQ, including MBF, has left residue in animalderived food samples, such as milk. The residue of FQ can be absorbed by the body, which can cause harmful health effects (Cheng et al., 2008; Käppeli et al., 2019). It has been reported that the abuse of $\mathrm{FQ}$, including $\mathrm{MBF}$, had caused side effects such as drug-resistant bacteria, phototoxicity, hemolytic uremic syndrome, thromboembolism, and central nervous system damage (Rutgersson et al., 2014; Wu et al., 2014; Wang et al., 2015, 2016).

To minimize the health risks to consumers, maximum residue limits for several FQ in food products of animal origin have been established by the European Union, the United States, Japan, the People's Republic of China, and the Food and Agriculture Organization of the United Nations (Tochi et al., 2016). For example, a maximum residue limit of $30 \mu \mathrm{g} / \mathrm{kg} \mathrm{MBF}$ is recommended for raw milk by the European Union (Regulation EC No. 470/2009; Chen et al., 2017). Furthermore, animals under the age of $1 \mathrm{yr}$ are banned from being treated with MBF (Dokuzeylül et al., 2019).

To monitor dairy product safety in a timely and effective manner, various analytical methodologies and immunoassays have been established for the detection of MBF in milk. Analytical methodologies include HPLC (Hermo et al., 2008; Li et al., 2011; Seyhan 
Bozkurt et al., 2016) and ultra-high performance liquid chromatography (Arroyo-Manzanares et al., 2015). However, these instrumental analytical methods have some disadvantages, such as expensive and intricate instruments, unsuitability for real-time field analysis, and time-consuming processes (Wang et al., 2007). By contrast, immunoassays, including indirect competitive (ic) ELISA and immunochromatographic assay based on specific antibody and antigen interactions, are easy to use, cheap, and sensitive (Peng et al., 2015). Sheng et al. (2009) developed a polyclonal antibody for the detection of MBF with a half-maximal inhibitory concentration $\left(\mathbf{I C}_{50}\right)$ of $4.6 \mathrm{ng} / \mathrm{mL}$ via ELISA. Sheng et al. (2011) prepared an anti-ofloxacin polyclonal antibody and used colloidal gold-based immunochromatographic assay (CGIA) to detect ofloxacin (OFL), MBF, and fleroxacin (FLE). Sheng et al. (2011) found that the limit of detection (LOD) in milk ranged from 3.5 to 8.9 $\mathrm{ng} / \mathrm{mL}$. Chen et al. (2017) created a polyclonal antibody against $\mathrm{MBF}$ and OFL. The $\mathrm{IC}_{50}$ of the antibody for detecting MBF and OFL via ic-ELISA was 0.76 and 2.70 $\mathrm{ng} / \mathrm{mL}$, respectively. These immunoassays are based on polyclonal antibodies prepared from New Zealand rabbits, but the polyclonal antibodies are nonrenewable and uneconomical for long-term use. Furthermore, to our knowledge, no reports are available about immunoassays based on a stable and reproducible mouse $\mathrm{mAb}$ against MBF. Peng et al. (2017a,b) developed a mAb named 1C9 against norfloxacin (NOR) and found that 1C9 showed a good cross-reactivity (CR) with MBF with $\mathrm{IC}_{50}$ of $1.15 \mathrm{ng} / \mathrm{mL}$. Peng et al. (2017a,b) also formulated a $\mathrm{mAb}$ named $3 \mathrm{E} 4$ against sarafloxacin (SAR) with cut-off value of $5 \mathrm{ng} / \mathrm{mL}$ for $\mathrm{MBF}$ in milk. Although mAb prepared by the immunogens of other FQ analogs have a large CR with MBF, the sensitivity of the detection of MBF has yet to be improved. Therefore, it is necessary to prepare a mAb specifically for MBF and apply it to the immunological methods.

This study aimed to generate a sensitive mouse $\mathrm{mAb}$ against MBF for economic purposes and strict regulation. Based on this mAb, an ic-ELISA was developed for the quantitative detection of MBF in milk, whereas a CGIA was established for the semiquantitative detection of MBF in milk.

\section{MATERIALS AND METHODS}

\section{Reagents and Instruments}

Marbofloxacin and 20 other analogs, namely FLE, lomefloxacin (LOM), NOR, OFL, pefloxacin (PEF), SAR, balofloxacin (BAL), besifloxacin (BES), cinoxa- cin (CIN), ciprofloxacin (CIP), danofloxacin (DAF), enrofloxacin (ENR), gatifloxacin (GAT), gemifloxacin (GEM), moxifloxacin (MOX), orbifloxacin (ORB), oxolinic acid (OXO), pazufloxacin (PAZ), prulifloxacin (PRU), and sparfloxacin (SPA), were obtained from Yuan Ye Biotechnology Co. Ltd. (Shanghai, China). A goat anti-mouse IgG antibody was obtained from Shanghai Youning Life Support Technology Co. Ltd. (Shanghai, China). Freund's adjuvant, Freund's incomplete adjuvant, 1-ethyl-3-(3-dimethylaminopropyl) carbodiimide, $N$-hydroxysuccinimide, albumin from BSA, and ovalbumin (OVA) were purchased from Sigma-Aldrich (St. Louis, MO). All other reagents and chemicals were obtained from National Pharmaceutical Group Chemical Reagent Co., Ltd. (Shanghai, China). The nitrocellulose (NC) membrane was supplied by Millipore (Bedford, MA). Polyvinylchloride (PVC) backing, sample, and absorbent pads were obtained from Shanghai Kinbio Tech. Co., Ltd. (Shanghai, China). Ten female BALB/c mice were obtained from the Nanchang University Animal Center (Nanchang, China). The milk samples were purchased from Rainbow Supermarket (Nanchang, China).

Polystyrene plates with 96 wells were supplied by Hangzhou Sheng-You Biotech Co. Ltd. (Hangzhou, China). An ELISA reader (Beijing Pulang New Technology Co. Ltd., Beijing, China) was used to detect optical density (OD). The UV-visible spectra of MBF-BSA, MBF-OVA, BSA, OVA, and MBF were obtained with a UV-visible spectrophotometer (UV-2300, Shimadzu, Kyoto, Japan). An XYZ-3050 platform and an automatic programmable cutter were obtained from BioDot (Irvine, CA). A portable gold nanoparticle (AuNP) reader was purchased from Zhejiang Fenghang Science Instrument Co. Ltd. (Zhejiang, China).

\section{Synthesis of Immunogens and Coating Antigens}

The immunogens and coating antigens were prepared by combining MBF with BSA and OVA, respectively, via a carbodiimide method. First, at room temperature, $0.01 \mathrm{~m} M \mathrm{MBF}, 0.04 \mathrm{~m} M$ 1-ethyl-3-(3-dimethylaminopropyl) carbodiimide, and $0.04 \mathrm{mM} \mathrm{N}$-hydroxysuccinimide were dissolved in $800 \mu \mathrm{L}$ of $0.01 M \mathrm{PBS}$ and stirred for $12 \mathrm{~h}$. Then, the reactants were added dropwise to $100 \mathrm{n} M$ BSA in $2 \mathrm{~mL}$ of $0.01 M$ carbonate buffer solution (CBS) and stirred overnight. The mixtures were dialyzed in $0.01 M$ PBS for $3 \mathrm{~d}$ to obtain an immunogen-marked MBF-BSA. The corresponding coating antigen-marked MBF-OVA was prepared in the same way. All immunogens and coating antigens were stored at $-20^{\circ} \mathrm{C}$ for further experiments. 


\section{Production of $m A b$}

Ten female BALB/c mice were injected with the immunogen by continuous subcutaneous injections at multiple points (Guo et al., 2015). The first immunization was administered using $100 \mu \mathrm{g} /$ mouse emulsified with Freund's complete adjuvant. Then the mice were boosted every $28 \mathrm{~d}$ for a total of 4 immunizations, each with a dosage of $50 \mu \mathrm{g}$ of immunogen emulsified with Freund's incomplete adjuvant. Seven days after the last immunization, a small amount of blood was taken from the mouse's tail, and the corresponding serum was evaluated through ic-ELISA with the corresponding coating antigen. The mouse with high affinity and inhibition ratio was conducted a final intraperitoneal injection of $25 \mu \mathrm{g}$ of immunogen. After $3 \mathrm{~d}$, the mouse was killed by breaking its neck, and its spleen was removed and fused with SP2/0 myeloma cells in an appropriate proportion between 2:1 and 10:1. After 7 $\mathrm{d}$ of culture in hypoxanthine-aminopterin-thymidine and hypoxanthine-thymidine solutions, only hybridoma cells survived, and their supernatants were measured through ic-ELISA. The hybridoma cells with high affinity and inhibition ratio were selected and cloned thrice with limited dilution to obtain monoclonal hybridoma cell lines. The selected hybridoma cells were injected into the abdomen of mice, and mice ascites were extracted after about $10 \mathrm{~d}$. Ascites were purified through ammonium sulfate precipitation to obtain $\mathrm{mAb}$ for further experiments.

\section{ELISA Procedure}

The ic-ELISA was carried out as described earlier $(\mathrm{Hu}$ et al., 2019). In brief, the coating antigen was added to a 96 -well plate at $100 \mu \mathrm{L} /$ well. After incubating at $37^{\circ} \mathrm{C}$ for $2 \mathrm{~h}$, the plate was washed thrice with $0.01 \mathrm{M}$ PBS containing $0.05 \%$ Tween 20 and sealed with $300 \mu \mathrm{L} /$ well of $0.01 M$ CBS containing $0.2 \%$ wt/vol gelatin at $37^{\circ} \mathrm{C}$ for $2 \mathrm{~h}$. After the plate was washed thrice, $50 \mu \mathrm{L}$ of $\mathrm{mAb}$ in antibody dilution solution (0.01 $M$ PBS with $0.1 \% \mathrm{wt} / \mathrm{vol}$ gelatin and $0.05 \% \mathrm{vol} / \mathrm{vol}$ Tween 20$)$ and $50 \mu \mathrm{L}$ of standards in PBS were added and incubated at $37^{\circ} \mathrm{C}$ for $30 \mathrm{~min}$. Afterward, the plate was washed thrice, and goat-anti-mouse IgG conjugated horseradish peroxidase (diluted 1:3,000 by antibody dilution buffer) was added at $100 \mu \mathrm{L} /$ well at $37^{\circ} \mathrm{C}$ for $30 \mathrm{~min}$. After incubation, the plate was washed 4 times, and TMB solution $(2 \mathrm{~mL}$ of ethylene glycol with $0.06 \% \mathrm{wt} / \mathrm{vol}$ TMB containing $10 \mathrm{~mL}$ of $0.1 M$ citric acid phosphate buffer, $\mathrm{pH} 5.0$, with $1.8 \mu \mathrm{L}$ of $30 \%$ hydrogen peroxide) was added at $100 \mu \mathrm{L} /$ well. Last, $50 \mu \mathrm{L}$ of $2 M \mathrm{H}_{2} \mathrm{SO}_{4}$ was added to terminate the reaction after incubation at $37^{\circ} \mathrm{C}$ for $15 \mathrm{~min}$, and the optical density was read by using a microplate reader at $450 \mathrm{~nm}\left(\mathbf{O D}_{450 \mathrm{~nm}}\right)$.

\section{Sensitivity and Specificity Evaluation}

Sigmoid curves were simulated with OriginPro 2016 (OriginLab Corp., Northampton, MA) to assess the $\mathrm{mAb}$. The $\mathbf{I C}_{\mathbf{2 0}}, \mathbf{I C}_{\mathbf{5 0}}$, and $\mathbf{I C}_{\mathbf{8 0}}$ were the concentrations of the analytes that provide a tracer binding inhibition in OD values at $20 \%, 50 \%$, and $80 \%$, respectively. In this study, $\mathrm{IC}_{50}$ value was used to estimate the sensitivity of $\mathrm{mAb}$. The $\mathrm{IC}_{20}$ value was defined as LOD, and the values between $\mathrm{IC}_{20}$ and $\mathrm{IC}_{80}$ were considered as the detection range of ic-ELISA. The $\mathrm{CR}$ values were counted as follows: $\mathrm{CR} \%=\left(\mathrm{IC}_{50}\right.$ of analyte $/ \mathrm{IC}_{50}$ of its analog) $\times 100$. Twenty FQ, namely OFL, ENR, OXO, CIN, PEF, LOM, FLE, CIP, NOR, DAF, ORB, SPA, GEM, BES, BAL, GAT, MOX, PAZ, PRU, and SAR, were tested.

\section{Preparation of AuNP-mAb}

Gold nanoparticles were synthesized as described previously (Sheng et al., 2011). In brief, $100 \mathrm{~mL}$ of 500 $\mu \mathrm{L}$ of $2 \% \mathrm{HAuCl}_{4}$ solution was boiled completely, and $1.65 \mathrm{~mL}$ of $1 \%$ trisodium citrate solution (wt/vol) was rapidly added under stirring. The mixtures were boiled for $10 \mathrm{~min}$ until the color changed to wine red and further boiled for another $10 \mathrm{~min}$. Then, the heating source was removed. Last, the solution was stored at $4^{\circ} \mathrm{C}$ for further experiments.

The AuNP-mAb were coupled as described earlier (Sheng et al., 2011). In brief, the purified antibody was added dropwise to the AuNP solution, and the $\mathrm{pH}$ was adjusted with $0.1 \mathrm{M} \mathrm{K}_{2} \mathrm{CO}_{3}$. After the solution was stirred for $1 \mathrm{~h}, 1 \%$ PEG was added while continuously stirring for $30 \mathrm{~min}$. Then, $10 \%$ (wt/vol) BSA was added drop by drop to block any unreacted sites. The mixtures were stirred again for $30 \mathrm{~min}$ and centrifuged at $4,450 \times g, 4^{\circ} \mathrm{C}$, for $20 \mathrm{~min}$. The AuNP-mAb were resuspended in PBS.

\section{Preparation of Immunochromatographic Test Strip}

An immunochromatographic test strip was packaged in our laboratory as described earlier (Sheng et al., 2011). In brief, the coating antigen $(0.6 \mathrm{mg} / \mathrm{mL}$ MBF-BSA) and the goat anti-mouse IgG $(1 \mathrm{mg} / \mathrm{mL})$ were sprayed on the NC membrane to form test lines and control lines ( $\mathbf{T}$ line and $\mathbf{C}$ line, respectively) at a 5 -mm interval. The $\mathrm{NC}$ membrane was dried at $37^{\circ} \mathrm{C}$ for $12 \mathrm{~h}$ and pasted to the middle of the PVC support plate. Then, the absorbent pad and the sample pad 


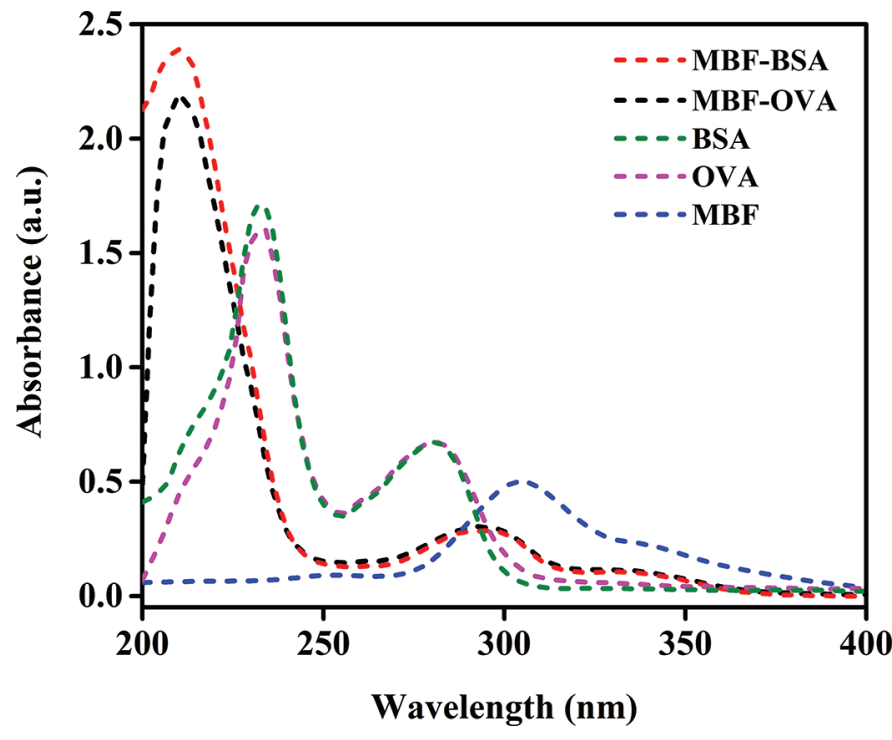

Figure 1. Ultraviolet-visible spectra of marbofloxacin (MBF)-BSA, MBF-ovalbumin (OVA), BSA, OVA, and MBF. a.u. = arbitrary units.

were attached to the upper and bottom sections of the plate, respectively, with $1.5 \mathrm{~mm}$ overlaps with the $\mathrm{NC}$ membrane. The paperboard was cut into $3 \mathrm{~mm} \times 60$ $\mathrm{mm}$ strips and kept in a desiccator at $37^{\circ} \mathrm{C}$ for further experiments.

\section{Immunochromatographic Test Strip Assay}

In this procedure, $100 \mu \mathrm{L}$ of the sample solution and $3 \mu \mathrm{L}$ of AuNP-mAb were added to a microtiter well, and the mixtures were reacted for 5 min at room temperature. Then, $100 \mu \mathrm{L}$ of the mixtures were added to the sample pad. The mixtures migrated from the sample pad via capillary action and passed through the $\mathrm{NC}$ membrane to react with the coating antigen on the $\mathrm{T}$ line and goat anti-mouse $\operatorname{IgG}$ on the $\mathrm{C}$ line within 15 min. The AuNP-mAb were captured by the coating antigen on the $\mathrm{T}$ line, forming deep color in the MBF-negative sample. The AuNP-mAb would take precedence to combine with $\mathrm{MBF}$ in the $\mathrm{MBF}$-positive sample. Thus, fewer AuNP-mAb were bound to coating antigens, resulting in lighter color on the $\mathrm{T}$ line. The higher the concentration of MBF was, the lighter the $\mathrm{T}$ line would be until it disappeared. The critical concentration was called as the cut-off value of the immunochromatographic test strip. In any instances, the MBF-AuNP-mAb or the AuNP-mAb mixtures would continue to move steadily and react quickly with the goat-mouse IgG antibody on the $\mathrm{C}$ line, resulting in a red color.

\section{Recovery Test}

The negative milk samples were confirmed with liquid chromatography-MS-MS by Jiangxi Institute of Veterinary Drug and Feedstuff Control (Nanchang, China) in Supplemental Figure S1 (https://doi.org/10 .3168/jds.2019-18108). Negative milk samples spiked with different concentrations of MBF were diluted 10 times with $0.01 M$ PBS and analyzed by using the developed ic-ELISA. Each test was repeated thrice.

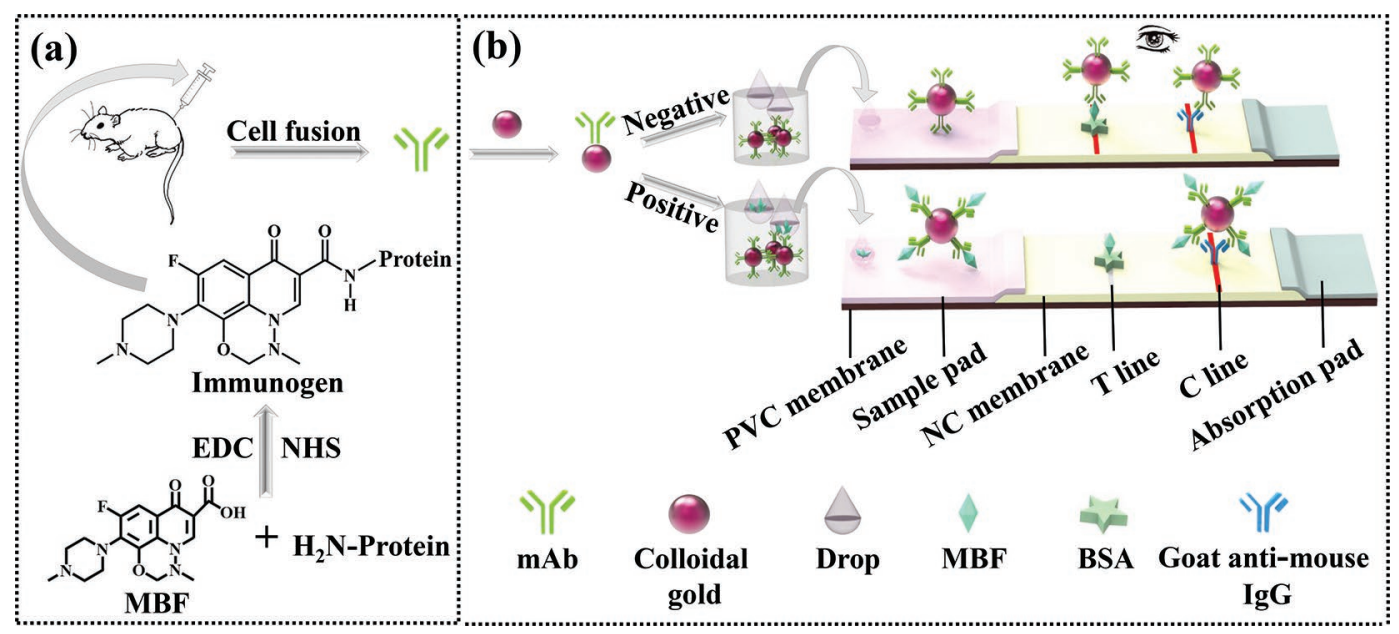

Figure 2. Schematic diagram of colloidal gold-based immunochromatographic assay (CGIA) based on mAb. (a) The preparation of anti-marbofloxacin (MBF) mAb. (b) The visual CGIA for detecting MBF. EDC = 1-ethyl-3-(3-dimethylaminopropyl) carbodiimide; NHS = $N$-hydroxysuccinimide; $\mathrm{PVC}=$ polyvinyl chloride; $\mathrm{NC}=$ nitrocellulose; $\mathrm{T}$ line $=$ test line; $\mathrm{C}$ line $=$ control line. 


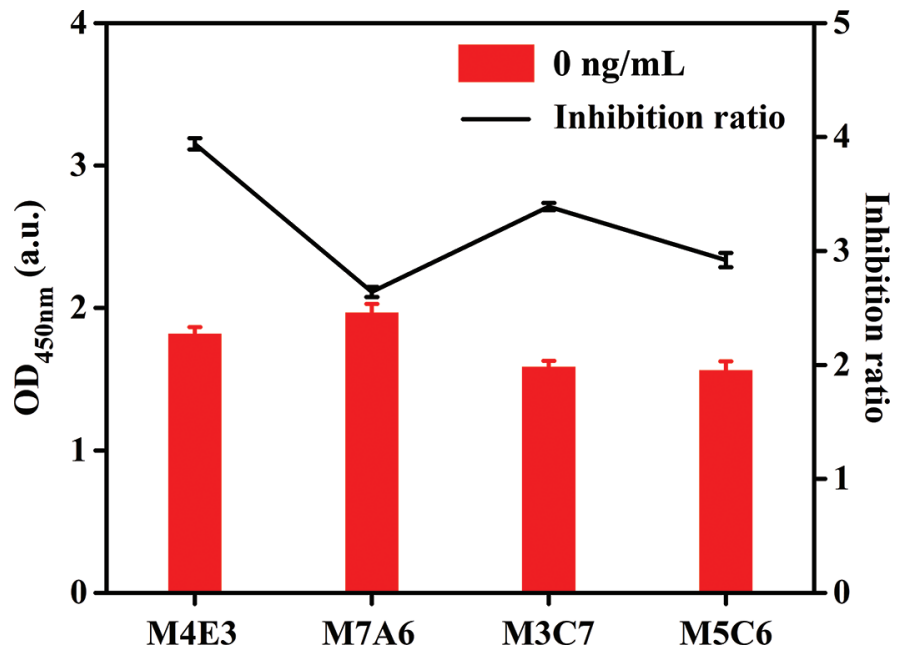

Figure 3. Comparison of optical density at $450 \mathrm{~nm}\left(\mathrm{OD}_{450 \mathrm{~nm}}\right)$ and inhibition ratio measured by $4 \mathrm{mAb}$ at the same concentration of coating antigen and antibody; 4 hybridoma cells were marked 4E3, 7A6, 3C7, and 5C6; 4 corresponding $\mathrm{mAb}$ were marked M4E3, M7A6, $\mathrm{M} 3 \mathrm{C} 7$, and M5C6. Inhibition ratio $=\mathrm{B}_{0} /\left(\mathrm{B} / \mathrm{B}_{0}\right)$, where $\mathrm{B}_{0}$ is the $\mathrm{OD}_{450 \mathrm{~mm}}$ of marbofloxacin $(\mathrm{MBF})$ standard $(0 \mathrm{ng} / \mathrm{mL})$ and $\mathrm{B}$ is the $\mathrm{OD}_{450 \mathrm{~nm}}$ of $\mathrm{MBF}$ standard $(1.1 \mathrm{ng} / \mathrm{mL})$. a.u. = arbitrary units. Error bars $=\mathrm{SD}$ of 3 replicates.
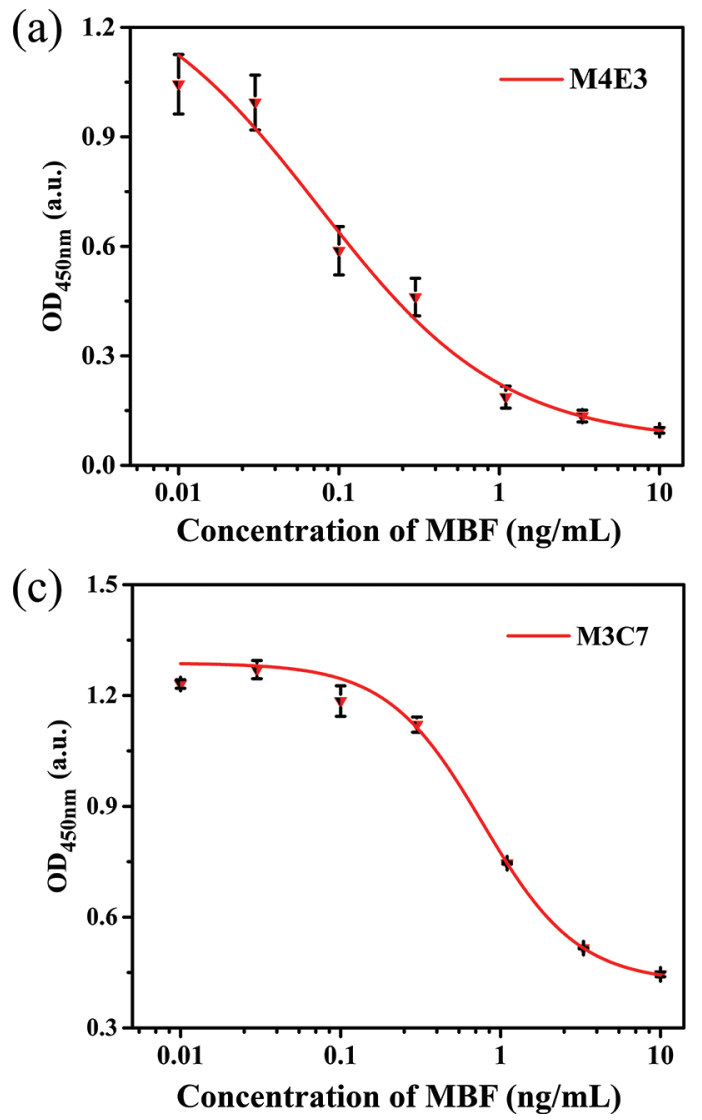

\section{RESULTS AND DISCUSSION}

\section{Antigen Preparation and Characterization}

The preparation of immunogen is important for antibody production. The molecular weight of MBF is less than 1,000 Da, which results it lacks of immunogenicity. To obtain antibodies, MBF should be bound to a carrier protein to initiate an immune response through a carboxyl group. Here, MBF was coupled with BSA and OVA, respectively, via the carbodiimide method for antigen preparation (i.e., MBF-BSA and MBF-OVA). Two conjugates were characterized using a UV-visible spectrophotometer (Figure 1). The UV absorption spectrum of MBF had 3 characteristic absorption peaks at 254,304, and $334 \mathrm{~nm}$, whereas the carrier proteins BSA and OVA both showed the same characteristic absorption peak at $278 \mathrm{~nm}$. Apparently, the MBF-BSA and MBF-OVA were successfully prepared as shown by 3 characteristic absorption peaks at 210, 296, and 332 $\mathrm{nm}$, which were well-known characteristic absorption peaks of carrier proteins and MBF.
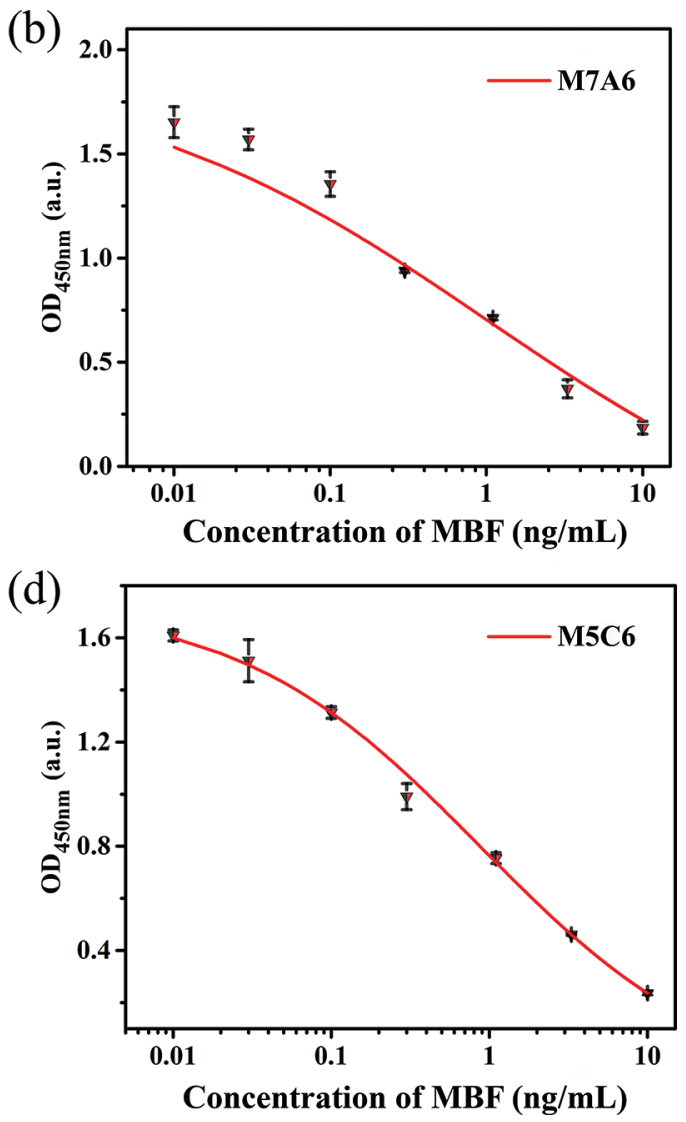

Figure 4. Sigmoid curves of $4 \mathrm{mAb}$ for detecting marbofloxacin (MBF) by indirect competitive (ic) ELISA; 4 hybridoma cells were marked 4E3, 7A6, 3C7, and 5C6; 4 corresponding mAb were marked M4E3, M7A6, M3C7, and M5C6. (a) Sigmoid curve of M4E3 for detecting MBF. (b) Sigmoid curve of M7A6 for detecting MBF. (c) Sigmoid curve of M3C7 for detecting MBF. (d) Sigmoid curve of M5C6 for detecting MBF by ic-ELISA. a.u. = arbitrary units. Error bars $=$ SD of 3 replicates. 


\section{Antibody Production and ELISA Evaluation}

Figure 2(a) showed the preparation of anti-MBF $\mathrm{mAb}$. The carboxyl-containing hapten and the aminocontaining protein were condensed by the carbodiimide method to obtain the whole antigen. Then the whole antigen was immunized to the mouse multiple times, and the mouse with the best inhibition ratio and titer for MBF were killed for fusion after antisera screening through ic-ELISA. In this study, 4 hybridoma cells marked 4E $3,7 \mathrm{~A} 6,3 \mathrm{C} 7$, and 5C6 were obtained and used to induce ascites tumors in mice and prepare ascites for antibody production. After antibody purification, 4 corresponding $\mathrm{mAb}$ that were marked M4E3, M7A6, M3C7, and M5C6 were obtained with concentrations of $11.20,7.88,14.80$, and $19.20 \mathrm{mg} / \mathrm{mL}$, respectively. First, $4 \mathrm{mAb}$ were evaluated by adding MBF standards ( 0 and $1.1 \mathrm{ng} / \mathrm{mL}$ ) with a coating antigen concentration of $0.3 \mu \mathrm{g} / \mathrm{mL}$ and $\mathrm{mAb}$ concentration of $0.3 \mu \mathrm{g} / \mathrm{mL}$. The $\mathrm{mAb}$ for further CGIA was determined based on the $\mathrm{OD}_{450 \mathrm{~nm}}$ of $\mathrm{MBF}$ standard $(0$ $\mathrm{ng} / \mathrm{mL})$ and inhibition ratio that is defined as $\mathrm{B}_{0} /(\mathrm{B} /$ $\mathrm{B}_{0}$ ) combined the performance of titer and inhibition, where $B_{0}$ is the $\mathrm{OD}_{450 \mathrm{~nm}}$ of MBF standard $(0 \mathrm{ng} / \mathrm{mL})$ and $\mathrm{B}$ is the $\mathrm{OD}_{450 \mathrm{~nm}}$ of MBF standard $(1.1 \mathrm{ng} / \mathrm{mL})$. As shown in Figure 3, the $\mathrm{OD}_{450 \mathrm{~nm}}$ value was the highest for M7A6 and was slightly lower for M4E3. However, the inhibition ratios of M4E3, M7A6, M3C7, and M5C6 were $3.94,2.64,3.39$, and 2.92 , respectively. Therefore, $\mathrm{M} 4 \mathrm{E} 3$, which showed the highest value of $\mathrm{B}_{0} /\left(\mathrm{B} / \mathrm{B}_{0}\right)$, was selected as the optimal $\mathrm{mAb}$ for further CGIA.

Based on previous studies, we used CBS ( $\mathrm{pH}$ 9.6) as a coating buffer and PBS (pH 7.4) as a standard dilution buffer (Wang et al., 2007; Tochi et al., 2016). In addition, the optimal concentration of coating antigen and each antibody were prepared via the checkerboard method before the establishment of standard curves. In terms of affinity and inhibition, the optimal concentrations of the coating antigens of M4E3, M7A6, $\mathrm{M} 3 \mathrm{C} 7$, and M5C6 were determined to be $0.03,0.03,0.3$, and $0.3 \mu \mathrm{g} / \mathrm{mL}$, respectively. The corresponding optimal concentrations of the antibodies of M4E3, M7A6, $\mathrm{M} 3 \mathrm{C} 7$, and M5C6 after dilution were determined to be $0.3,0.3,0.3$, and $0.3 \mu \mathrm{g} / \mathrm{mL}$, respectively. Different concentrations of MBF standards (0, 0.01, 0.03, 0.11, 0.33, $1.1,3.3$, and $10 \mathrm{ng} / \mathrm{mL}$ ) were prepared, and ic-ELISA was developed to evaluate the sensitivity of $4 \mathrm{mAb}$ with corresponding optimal working conditions. Each point represented the mean \pm standard deviation of 3 replicates. As shown in Figures 4 and 5, sigmoid curves were determined using MBF-OVA as a coating antigen. For M4E3, the $\mathrm{IC}_{50}$, LOD, and linear range of detection $\left(\mathrm{IC}_{20}-\mathrm{IC}_{80}\right)$ were $0.07,0.01$, and $0.01-0.47 \mathrm{ng} / \mathrm{mL}$, re- spectively. For M7A6, the $\mathrm{IC}_{50} \mathrm{LOD}$, and linear range of detection $\left(\mathrm{IC}_{20}-\mathrm{IC}_{80}\right)$ were 1.03, 0.02, and 0.02-47.18 $\mathrm{ng} / \mathrm{mL}$, respectively. For $\mathrm{M} 3 \mathrm{C} 7$, the $\mathrm{IC}_{50}$, LOD, and linear range of detection $\left(\mathrm{IC}_{20}-\mathrm{IC}_{80}\right)$ were $0.77,0.30$, and $0.30-2.00 \mathrm{ng} / \mathrm{mL}$, respectively. For M5C6, the $\mathrm{IC}_{50}$, $\mathrm{LOD}$, and linear range of detection $\left(\mathrm{IC}_{20}-\mathrm{IC}_{80}\right)$ were $0.88,0.08$, and $0.08-10.23 \mathrm{ng} / \mathrm{mL}$, respectively. These $4 \mathrm{mAb}$ exhibited high sensitivity and affinity. Among these antibodies, M4E3, which exhibited the highest sensitivity with an $\mathrm{IC}_{50}$ of $0.07 \mathrm{ng} / \mathrm{mL}$, was selected to develop the method of ic-ELISA and CGIA.

The CR of $20 \mathrm{FQ}$ analogs was tested on the basis of different $\mathrm{mAb}$ to evaluate the broad specificity. As
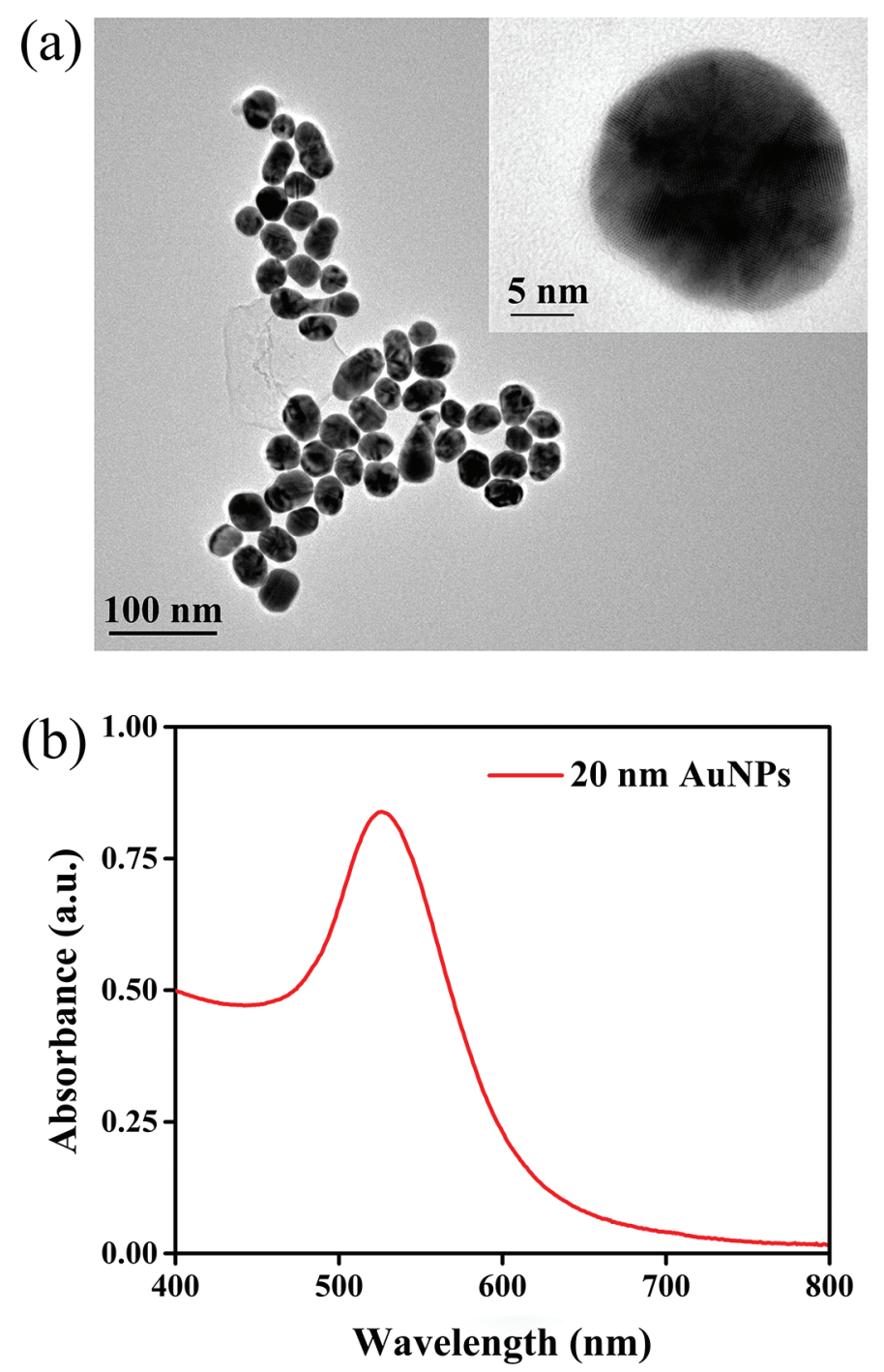

Figure 5. Characterization of the gold nanoparticle (AuNP) solution: (a) transmission electron microscopy images of $20 \mathrm{~nm}$ AuNP and (b) UV-visible spectra of AuNP with a maximum absorption wavelength at $526 \mathrm{~nm}$. a.u. = arbitrary units. 
shown in Table 1 , among these $4 \mathrm{mAb}$, OFL showed a good CR exceeding 100\% mainly because of its highly similar structure. Sheng et al. (2009) and Chen et al. (2017) also confirmed this finding. Moreover, the CR with FLE was over $31.89 \%$, which was consistent with $39 \%$ reported by Sheng et al. (2011). However, Chen et al. (2017) did not evaluate the CR with FLE. For LOM and DAF, the produced $\mathrm{mAb}$ had appropriate CR exceed $24.49 \%$ and $11 \%$, which were the first reported values. The other references were either not measured or had an extremely weak CR. In addition, different $\mathrm{mAb}$ have different $\mathrm{CR}$ trends for different drugs. For example, M4E3 and M7A6 showed a large CR of $354.79 \%$ and $204.55 \%$ with LOM, whereas M3C7 and M5C6 showed a CR of $59.17 \%$ and $24.49 \%$ with it, which is a difference of nearly 15 -fold. For NOR, M4E3 had a CR of $0.69 \%$, but the 3 other $\mathrm{mAb}$ have a CR of less than $0.1 \%$. Here, for M4E3, as many as 6 FQ analogs, namely LOM, OFL, FLE, PEF, DAF, and ENR, had a good CR exceeding $20 \%$ with $\mathrm{IC}_{50}$ of 0.02 , $0.07,0.18,0.27,0.30$, and $0.32 \mathrm{ng} / \mathrm{mL}$, respectively. The results are encouraging because OFL, PEF, and LOM had been banned by the Ministry of Agriculture of China (No. 2292). In addition, a weak CR was ob- served in other $\mathrm{FQ}$ analogs. Given the possibility of $\mathrm{CR}$, as many FQ analogs as possible, especially LOM, OFL, FLE, PEF, DAF, and ENR, were recommended to be evaluated in the $\mathrm{CR}$ experiments against $\mathrm{MBF}$.

\section{Recovery Test}

The stability and reproducibility of the ic-ELISA were evaluated through intraassay and interassay by using MBF-spiked milk samples at different concentrations of $0.1,0.5$, and $2.5 \mathrm{ng} / \mathrm{mL}$. The intraassay was conducted within $1 \mathrm{~d}$ with 3 replicates at different spiking levels, and the interassay was carried out over 3 consecutive days. As shown in Table 2, the good coefficients of variation ranged from $4.32 \%$ to $7.44 \%$ in intraassay and from $2.39 \%$ to $6.04 \%$ in interassay. It was concluded that the developed ic-ELISA could detect MBF stability and reproducibility in milk samples. In addition, good recoveries (72.28-129.19\%) were obtained after sample analysis with 3 replicates. Meanwhile, the reproducibility $(\mathrm{n}=3)$ showed that the standard deviation ranged from 0.01 to 0.03 , revealing good precision of the ic-ELISA for detecting MBF in milk samples.

Table 1. Half-maximal inhibitory concentration $\left(\mathrm{IC}_{50} ; \mathrm{ng} / \mathrm{mL}\right)$ and cross-reactivity $(\mathrm{CR}, \%)$ of 20 fluoroquinolone analogs by indirect competitive ELISA based on different mAb; 4 hybridoma cells were marked 4E3, 7A6, 3C7, and 5C6; 4 corresponding mAb were marked M4E3, M7A6, $\mathrm{M} 3 \mathrm{C} 7$, and $\mathrm{M} 5 \mathrm{C} 6$

\begin{tabular}{|c|c|c|c|c|c|c|c|c|}
\hline \multirow[b]{2}{*}{ Drug $^{1}$} & \multicolumn{2}{|c|}{ M4E3 } & \multicolumn{2}{|c|}{ M7A6 } & \multicolumn{2}{|c|}{ M3C7 } & \multicolumn{2}{|c|}{ M5C6 } \\
\hline & $\mathrm{IC}_{50}$ & $\mathrm{CR}$ & $\mathrm{IC}_{50}$ & $\mathrm{CR}$ & $\mathrm{IC}_{50}$ & $\mathrm{CR}$ & $\mathrm{IC}_{50}$ & $\mathrm{CR}$ \\
\hline $\mathrm{MBF}$ & 0.07 & 100.00 & 1.03 & 100.00 & 0.77 & 100.00 & 0.88 & 100.00 \\
\hline LOM & 0.02 & 354.79 & 0.50 & 204.55 & 1.30 & 59.17 & 3.59 & 24.49 \\
\hline OFL & 0.07 & 100.00 & 1.03 & 100.00 & 0.69 & 111.11 & 0.82 & 107.86 \\
\hline FLE & 0.18 & 39.40 & 2.63 & 39.13 & 1.45 & 53.19 & 2.76 & 31.89 \\
\hline $\mathrm{PEF}$ & 0.27 & 25.65 & 5.72 & 18.00 & 2.62 & 29.41 & 10.08 & 8.73 \\
\hline $\mathrm{DAF}$ & 0.30 & 23.71 & 5.20 & 19.82 & 2.27 & 33.90 & 8.00 & 11.00 \\
\hline ENR & 0.32 & 21.84 & 68.70 & 1.50 & 8.47 & 9.09 & 9.17 & 9.60 \\
\hline PRU & 6.30 & 1.11 & 762.57 & 0.14 & 432.74 & 0.18 & $>1,000$ & $<0.10$ \\
\hline NOR & 10.20 & 0.69 & $>1,000$ & $<0.10$ & $>1,000$ & $<0.08$ & $>1,000$ & $<0.10$ \\
\hline CIP & 11.32 & 0.62 & $>1,000$ & $<0.10$ & 246.40 & 0.31 & 458.35 & 0.19 \\
\hline GAT & 63.14 & 0.11 & $>1,000$ & $<0.10$ & $>1,000$ & $<0.08$ & $>1,000$ & $<0.10$ \\
\hline BAL & 150.19 & 0.05 & $>1,000$ & $<0.10$ & $>1,000$ & $<0.08$ & $>1,000$ & $<0.10$ \\
\hline MOX & 425.00 & 0.02 & $>1,000$ & $<0.10$ & $>1,000$ & $<0.08$ & $>1,000$ & $<0.10$ \\
\hline SAR & 427.00 & 0.02 & $>1,000$ & $<0.10$ & $>1,000$ & $<0.08$ & $>1,000$ & $<0.10$ \\
\hline SPA & $>1,000$ & $<0.01$ & $>1,000$ & $<0.10$ & $>1,000$ & $<0.08$ & $>1,000$ & $<0.10$ \\
\hline CIN & $>1,000$ & $<0.01$ & $>1,000$ & $<0.10$ & $>1,000$ & $<0.08$ & $>1,000$ & $<0.10$ \\
\hline BES & $>1,000$ & $<0.01$ & $>1,000$ & $<0.10$ & $>1,000$ & $<0.08$ & $>1,000$ & $<0.10$ \\
\hline GEM & $>1,000$ & $<0.01$ & $>1,000$ & $<0.10$ & $>1,000$ & $<0.08$ & $>1,000$ & $<0.10$ \\
\hline PAZ & $>1,000$ & $<0.01$ & $>1,000$ & $<0.10$ & $>1,000$ & $<0.08$ & $>1,000$ & $<0.10$ \\
\hline ORB & $>1,000$ & $<0.01$ & $>1,000$ & $<0.10$ & $>1,000$ & $<0.08$ & $>1,000$ & $<0.10$ \\
\hline $\mathrm{OXO}$ & $>1,000$ & $<0.01$ & $>1,000$ & $<0.10$ & $>1,000$ & $<0.08$ & $>1,000$ & $<0.10$ \\
\hline
\end{tabular}

${ }^{1} \mathrm{MBF}=$ marbofloxacin; LOM = lomefloxacin; OFL = ofloxacin; FLE = fleroxacin; PEF = pefloxacin; DAF = danofloxacin; ENR = enrofloxa-

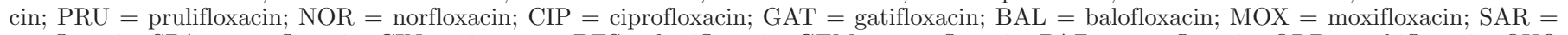
sarafloxacin; SPA = sparfloxacin; CIN = cinoxacin; BES = besifloxacin; GEM = gemifloxacin; PAZ = pazufloxacin; ORB = orbifloxacin; OXO $=$ oxolinic acid. 
Table 2. Recoveries of marbofloxacin (MBF) in milk by indirect competitive ELISA

\begin{tabular}{lccccc}
\hline & & & & \multicolumn{2}{c}{ CV $(\% ; \mathrm{n}=3)$} \\
\cline { 5 - 6 } Sample & $\begin{array}{c}\text { Spiked MBF } \\
(\mathrm{ng} / \mathrm{mL})\end{array}$ & $\begin{array}{c}\text { Mean } \pm \text { SD } \\
(\mathrm{ng} / \mathrm{mL})\end{array}$ & Recovery $(\%)$ & Intraassay & Interassay \\
\hline Milk & 0.1 & $0.12 \pm 0.01$ & 129.19 & 7.44 & 6.04 \\
& 0.5 & $0.45 \pm 0.02$ & 90.94 & 4.43 & 4.08 \\
& 2.5 & $1.80 \pm 0.03$ & 72.28 & 4.32 & 2.39 \\
\hline
\end{tabular}

\section{Immunochromatographic Test Strip Assay}

The visibility of CGIA is based on the red color of the AuNP. In this work, $20 \mathrm{~nm}$ AuNP were selected for labeling the $\mathrm{mAb}$ (Guo et al., 2015). The transmission electron microscopy images of AuNP and UV-visible spectra of AuNP in Figure 5 exhibited the morphological characteristics and size of AuNP. The synthesized AuNP had good dispersity and uniformity with an average size of $20 \mathrm{~nm}$ in Figure 5(a). As shown in Figure 5(b), the AuNP had a maximum UV absorption wavelength at $526 \mathrm{~nm}$, which indicated that the AuNP were successfully prepared. Since the $\mathrm{pH}$, the concentration of MBF-BSA on the T line, and the amount of the labeled antibody play key roles in the immunochromatographic test strip, different values of $\mathrm{pH}(5,6,7,8$, and 9 ), different concentrations of MBF-BSA on the $\mathrm{T}$ line $(0.2,0.4,0.6$, and $0.8 \mathrm{mg} / \mathrm{mL})$, and different amounts of the labeled antibody $(4,6,8,10$, and $12 \mu \mathrm{g}$ in $1 \mathrm{~mL}$ AuNP solution) were optimized. In this work, the value of $\mathrm{pH}$ was selected as 6 to form AuNP-mAb because the labeling efficiency increased when the $\mathrm{pH}$ increased from 5 to 6 and then dropped off quickly with the $\mathrm{pH}$ increasing from 6 to 9 [Supplemental Figure S2(a), https://doi.org/10.3168/jds.2019-18108]. In addition, the optimal concentration of MBF-BSA on the T line was $0.6 \mathrm{mg} / \mathrm{mL}$ and the amount of labeled $\mathrm{mAb}$ was $10 \mu \mathrm{g}$ in $1 \mathrm{~mL}$ of AuNP solution with the high signal of $\mathrm{T}$ line and the high inhibition ratio [Supplemental Figures S2(b) and S2(c), https://doi.org/10.3168/jds .2019-18108].

Figure 2(b) showed the CGIA for detecting MBF. In the absence of $\mathrm{MBF}$, both the $\mathrm{T}$ line and the $\mathrm{C}$ line turned red. A higher concentration of MBF resulted in a weaker red color of the $\mathrm{T}$ line because the probes conjugated to MBF first and fewer probes bound to MBF-BSA on the $\mathrm{T}$ line. Thus, in the high concentration of MBF, only the $\mathrm{C}$ line turned red.

The test strip was tested in 0.01 $M$ PBS and milk samples. As Figure 6(a) shown, deep red color was observed clearly on the $\mathrm{T}$ line with the naked eye when 0 $\mathrm{ng} / \mathrm{mL} \mathrm{MBF}$ was added in PBS. The color on the T line became weaker when the concentration of MBF was increased. The color on the $\mathrm{T}$ line disappeared completely when the concentration of MBF was increased to $1 \mathrm{ng} /$ $\mathrm{mL}$. Therefore, $1 \mathrm{ng} / \mathrm{mL}$ was set as the cut-off value to assess strip sensitivity in PBS. Similarly, as Figure 6(b) shown, the color on the $\mathrm{T}$ line almost disappeared when the concentration of MBF was increased to $1 \mathrm{ng} / \mathrm{mL}$ in milk. Thus, in milk samples, the cut-off value on the $\mathrm{T}$ line was $1 \mathrm{ng} / \mathrm{mL}$, too. The matrix interferences were eliminated by diluting spiked milk 10 times, resulting in the same cut-off values in milk. These results confirmed that the developed CGIA could be an effective method for the detection of MBF in milk samples. To confirm the stability and reproducibility of CGIA, the above results were carried out over 3 consecutive days. All the results showed that the color on the $\mathrm{T}$ line almost disappeared when the concentration of MBF was increased to $1 \mathrm{ng} / \mathrm{mL}$ in milk samples (Supplemental Figure S3; https://doi.org/10.3168/jds.2019-18108). Therefore, we concluded that the test strips could be stable and reproducible for the detection of $\mathrm{MBF}$ in milk samples.
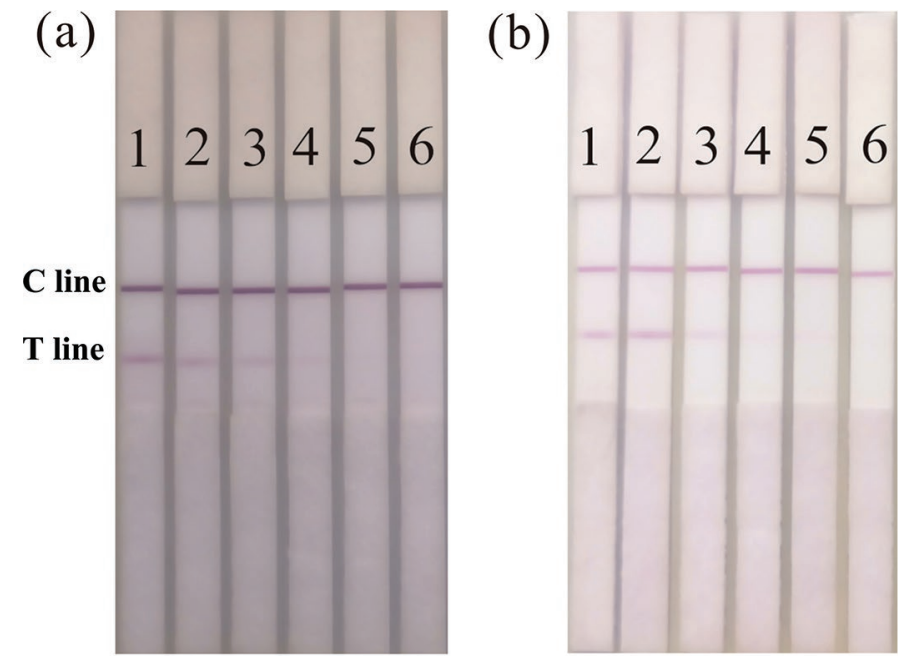

Figure 6. Images of the detection of marbofloxacin (MBF) using the visual colloidal gold-based immunochromatographic assay in (a) $0.01 M$ PBS and (b) milk samples. (a) Different concentrations of MBF spiked in 0.01 $M$ PBS. (b) Different concentrations of MBF spiked in milk samples $(1=0 \mathrm{ng} / \mathrm{mL}, 2=0.1 \mathrm{ng} / \mathrm{mL}, 3=0.25 \mathrm{ng} /$ $\mathrm{mL}, 4=0.5 \mathrm{ng} / \mathrm{mL}, 5=1 \mathrm{ng} / \mathrm{mL}, 6=5 \mathrm{ng} / \mathrm{mL})$. T line $=$ test line; $\mathrm{C}$ line $=$ control line. 


\section{CONCLUSIONS}

In this study, 4 sensitive $\mathrm{mAb}$ against MBF were successfully generated. An ic-ELISA based on a sensitive $\mathrm{mAb}$ M4E3 was developed with an $\mathrm{IC}_{50}$ of $0.07 \mathrm{ng} / \mathrm{mL}$ and a LOD of $0.01 \mathrm{ng} / \mathrm{mL}$ for the quantitative detection of MBF. Furthermore, this mAb had a good CR that exceeded $20 \%$ with $6 \mathrm{FQ}$ analogs, namely LOM, OFL, DAF, FLE, PEF, and ENR. The recovery test showed that the average recovery of MBF ranged from $72.28 \%$ to $129.19 \%$ in milk samples. Moreover, a visual CGIA was developed with a cut-off value of $1 \mathrm{ng} / \mathrm{mL}$ in both $0.01 M$ PBS and milk samples for the detection of MBF. Given the sensitive M4E3, the developed ic-ELISA and CGIA could be useful tools for screening $\mathrm{MBF}$ residue in milk samples, avoiding the abuse of $\mathrm{FQ}$ in animal farming and protecting public health.

\section{ACKNOWLEDGMENTS}

This work was supported by the National Science Foundation for Young Scientists of China (31800776), Key Research and Development Program of Jiangxi Province (20192BBF60046, China). The authors declare no competing financial interest.

\section{REFERENCES}

Altan, F., D. N. Sayin Ipek, O. Corum, S. Yesilmen Alp, P. Ipek, and K. Uney. 2019. The effects of Mannheimia haemolytica and albendazole on marbofloxacin pharmacokinetics in lambs. Trop. Anim. Health Prod. 51:2603-2610. https://doi.org/10.1007/s11250-019 $-01980-5$.

Arroyo-Manzanares, N., J. F. Huertas-Perez, M. Lombardo-Agui, L. Gamiz-Gracia, and A. M. Garcia-Campana. 2015. A high-throughput method for the determination of quinolones in different matrices by ultra-high performance liquid chromatography with fluorescence detection. Anal. Methods 7:253-259. https://doi.org/10 .1039/C4AY01940G.

Balikci, E., O. Kizil, T. Karapinar, M. Karahan, H. Ozdemir, and M. Dabak. 2008. Efficacy of marbofloxacin for naturally occurring contagious caprine pleuropneumonia. Small Rumin. Res. 77:75-79. https://doi.org/10.1016/j.smallrumres.2008.02.009.

Chen, X. J., Z. Z. Li, J. Y. Guo, D. M. Li, H. L. Gao, Y. Wang, and C. L. Xu. 2017. Simultaneous screening for marbofloxacin and ofloxacin residues in animal-derived foods using an indirect competitive immunoassay. Food Agric. Immunol. 28:489-499. https://doi.org/ 10.1080/09540105.2017.1297780.

Cheng, G. W., H. L. Wu, and Y. L. Huang. 2008. Simultaneous determination of malondialdehyde and ofloxacin in plasma using an isocratic high-performance liquid chromatography/fluorescence detection system. Anal. Chim. Acta 616:230-234. https://doi.org/ 10.1016/j.aca.2008.04.012.

Dokuzeylül, B., B. Çelik, B. D. Siğirci, B. B. Kahraman, S. Ü. Saka, A. Kayar, S. Ak, and E. O. M. 2019. Clinical efficacy of marbofloxacin in dogs and cats diagnosed with lower urinary tract disorders. Med. Weter. 75:549-552. https://doi.org/10.21521/mw.6269.

Guo, L., S. S. Song, L. Q. Liu, J. Peng, H. Kuang, and C. L. Xu. 2015. Comparison of an immunochromatographic strip with ELISA for simultaneous detection of thiamphenicol, florfenicol and chloramphenicol in food samples. Biomed. Chromatogr. 29:1432-1439. https://doi.org/10.1002/bmc.3442.
Hermo, M. P., E. Nemutlu, S. Kır, D. Barrón, and J. Barbosa. 2008. Improved determination of quinolones in milk at their MRL levels using LC-UV, LC-FD, LC-MS and LC-MS/MS and validation in line with regulation 2002/657/EC. Anal. Chim. Acta 613:98-107. https://doi.org/10.1016/j.aca.2008.02.045.

Hoeltig, D., J. Rohde, B. Brunner, K. Hellmann, E. Grandemange, and K. H. Waldmann. 2018. Efficacy of a one-shot marbofloxacin treatment on acute pleuropneumonia after experimental aerosol inoculation of nursery pigs. Porcine Health Manag. 4:13-22. https: //doi.org/10.1186/s40813-018-0089-2.

Hu, S., B. L. Fang, Z. Huang, Y. Chen, D. F. Liu, K. Y. Xing, J. Peng, and W. H. Lai. 2019. Using molecular descriptors for assisted screening of heterologous competitive antigens to improve the sensitivity of ELISA for detection of enrofloxacin in raw milk. J. Dairy Sci. 102:6037-6046. https://doi.org/10.3168/jds.2018-16048.

Käppeli, N., M. Morach, S. Corti, C. Eicher, R. Stephan, and S. Johler. 2019. Staphylococcus aureus related to bovine mastitis in Switzerland: Clonal diversity, virulence gene profiles, and antimicrobial resistance of isolates collected throughout 2017. J. Dairy Sci. 102:3274-3281. https://doi.org/10.3168/jds.2018-15317.

Li, Y., Z. J. Zhang, J. S. Li, H. G. Li, Y. Chen, and Z. H. Liu. 2011. Simple, stable and sensitive electrogenerated chemiluminescence detector for high-performance liquid chromatography and its application in direct determination of multiple fluoroquinolone residues in milk. Talanta 84:690-695. https://doi.org/10.1016/j .talanta.2011.01.068.

Peng, J., D. Z. Kong, L. Q. Liu, S. S. Song, H. Kuang, and C. L. $\mathrm{Xu}$. 2015. Determination of quinoxaline antibiotics in fish feed by enzyme-linked immunosorbent assay using a monoclonal antibody. Anal. Methods 7:5204-5209. https://doi.org/10.1039/ C5AY00953G.

Peng, J., L. Q. Liu, H. Kuang, G. Cui, and C. L. Xu. 2016. Development of an icELISA and immunochromatographic strip for detection of norfloxacin and its analogs in milk. Food Agric. Immunol. 28:288-298. https://doi.org/10.1080/09540105.2016.1263987.

Peng, J., L. Q. Liu, L. G. Xu, S. S. Song, H. Kuang, G. Cui, and C. L. Xu. 2017. Gold nanoparticle-based paper sensor for ultrasensitive and multiple detection of 32 (fluoro)quinolones by one monoclonal antibody. Nano Res. 10:108-120. https://doi.org/10.1007/s12274 $-016-1270-z$

Pham, T. D. M., Z. M. Ziora, and M. A. T. Blaskovich. 2019. Quinolone antibiotics. Medchemcomm. 10:1719-1739.

Rusch, M., A. Spielmeyer, J. Meissner, M. Kietzmann, H. Zorn, and G. Hamscher. 2017. Efficient reduction of antibacterial activity and cytotoxicity of fluoroquinolones by fungal-mediated N-oxidation. J. Agric. Food Chem. 65:3118-3126. https://doi.org/10.1021/acs .jafc.7b01246.

Rutgersson, C., J. Fick, N. Marathe, E. Kristiansson, A. Janzon, M. Angelin, A. Johansson, Y. Shouche, C. F. Flach, and D. G. J. Larsson. 2014. Fluoroquinolones and $q n r$ genes in sediment, water, soil, and human fecal flora in an environment polluted by manufacturing discharges. Environ. Sci. Technol. 48:7825-7832. https:/ /doi.org/10.1021/es501452a.

Seyhan Bozkurt, S., D. Erdogan, M. Antep, N. Tuzmen, and M. Merdivan. 2016. Use of ionic liquid based chitosan as sorbent for preconcentration of fluoroquinolones in milk, egg, fish, bovine, and chicken meat samples by solid phase extraction prior to HPLC determination. J. Liq. Chromatogr. Relat. Technol. 39:21-29. https: //doi.org/10.1080/10826076.2015.1116010.

Sheng, W., Y. Z. Li, X. Xu, M. Yuan, and S. Wang. 2011. Enzymelinked immunosorbent assay and colloidal gold-based immunochromatographic assay for several (fluoro)quinolones in milk. Microchim. Acta 173:307-316. https://doi.org/10.1007/s00604-011-0560 -0 .

Sheng, W., X. Xia, K. Wei, J. Li, Q. X. Li, and T. Xu. 2009. Determination of marbofloxacin residues in beef and pork with an enzymelinked immunosorbent assay. J. Agric. Food Chem. 57:5971-5975. https://doi.org/10.1021/jf900940n

Tochi, B. N., G. Khaemba, J. Isanga, D. Mukunzi, L. Q. Liu, J. Peng, H. Kuang, and C. L. Xu. 2016. Monoclonal antibody for the development of specific immunoassays to detect Enrofloxacin in foods of 
animal origin. Food Agric. Immunol. 27:435-448. https://doi.org/ 10.1080/09540105.2015.1089844.

Wang, H., B. Wang, Q. Zhao, Y. P. Zhao, C. W. Fu, X. Feng, N. Wang, M. F. Su, C. X. Tang, F. Jiang, Y. Zhou, Y. Chen, and Q. W. Jiang. 2015. Antibiotic body burden of Chinese school children: A multisite biomonitoring-based study. Environ. Sci. Technol. 49:5070-5079. https://doi.org/10.1021/es5059428.

Wang, H., N. Wang, B. Wang, H. Fang, C. W. Fu, C. X. Tang, F. Jiang, Y. Zhou, G. S. He, Q. Zhao, Y. Chen, and Q. W. Jiang. 2016. Antibiotics detected in urines and adipogenesis in school children. Environ. Int. 89-90:204-211. https://doi.org/10.1016/j .envint.2016.02.005
Wang, Z., Y. Zhu, S. Y. Ding, F. Y. He, R. C. Beier, J. C. Li, H. Y. Jiang, C. W. Feng, Y. P. Wan, S. X. Zhang, Z. P. Kai, X. L. Yang, and J. Z. Shen. 2007. Development of a monoclonal antibodybased broad-specificity ELISA for fluoroquinolone antibiotics in foods and molecular modeling studies of cross-reactive compounds. Anal. Chem. 79:4471-4483. https://doi.org/10.1021/ac070064t.

Wu, X. L., L. Xiang, Q. Y. Yan, Y. N. Jiang, Y. W. Li, X. P. Huang, H. Li, Q. Y. Cai, and C. H. Mo. 2014. Distribution and risk assessment of quinolone antibiotics in the soils from organic vegetable farms of a subtropical city. Southern China Sci. Total Environ. 487:399-406. https://doi.org/10.1016/j.scitotenv.2014.04.015. 